\title{
Stakeholder engagement via Facebook: an analysis of world's most popular museums
}

\section{Vincenzo Scafarto*}

Department of Human, Social and Health Sciences, University of Cassino and Southern Lazio,

Cassino, Italy

Email: vscaf@hotmail.com

*Corresponding author

\section{Federica Ricci and Gaetano della Corte}

Department of Law and Economics of Productive Activities,

University of Rome 'Sapienza',

Rome, Italy

Email: fede.ricci@uniroma1.it

Email: gaetano.dellacorte@hotmail.it

\section{Carla Morrone}

Department of Business and Economics, University of Naples 'Parthenope',

Naples, Italy

Email: carlamorrone@hotmail.it

\begin{abstract}
Over the last few years, social media (SM) have been emphasised as a means for organisations to foster stakeholder relationship with particular stress on their potential to promote community building and dialogic engagement with online audiences. These potential benefits of SM have been claimed also with respect to cultural organisations. However, the available research evidence on SM and museums suggests that museums still struggle to exploit these tools to their full potential. This paper adds further evidence on this issue by empirically investigating whether museums are using Facebook to promote follower engagement using a sample of top-attended museums worldwide. Results suggest that the frequency and content type of posts correlate to some extent with the degree of follower reactions. Nevertheless, sample museums predominantly use SM to publish promotional contents and as a result fail to achieve a true 'dialogic' follower engagement.
\end{abstract}

Keywords: Facebook; follower engagement; social media; museums.

Reference to this paper should be made as follows: Scafarto, V., Ricci, F., della Corte, G. and Morrone, C. (2020) 'Stakeholder engagement via Facebook: an analysis of world's most popular museums', Int. J. Digital Culture and Electronic Tourism, Vol. 3, No. 1, pp.6-21.

Biographical notes: Vincenzo Scafarto is an Assistant Professor of Business Economics at the University of Cassino and Southern Lazio, Department of Human, Social and Health Sciences. He received his $\mathrm{PhD}$ in Business 
Administration from the University of Neaples 'Federico II', Italy. His research interests range from intellectual capital accounting to sports economics, firm internationalisation and history of accounting.

Federica Ricci is a researcher in Business Economics at the University of Rome 'La Sapienza', Department of Law and Economics of Productive Activities. Her research interests include intellectual capital accounting, corporate governance, leadership and corporate social responsibility.

Gaetano della Corte is a Research Fellow at the University of Rome 'Sapienza', Department of Law and Economics of Productive Activities. His current research focuses on corporate governance, strategic intelligence and social networking strategy.

Carla Morrone is a PhD student at the University of Naples 'Parthenope', Department of Business and Economics. She is also a freelance accountant and statutory auditor. Her current research focuses on value creation and corporate social responsibility.

\section{Introduction}

In the last few years, social media (SM) have been emphasised as a means for organisations to foster stakeholder relations placing a particular stress on their potential to promote the formation of online communities engaged in a dialogic exchange of knowledge.

Kaplan and Haenlein (2010) define SM as "a group of internet-based applications that build on the ideological and technological foundations of Web 2.0, and that allow the creation and exchange of user-generated content (UGC)."

SM appear in various forms, such as blogs, micro blogs (e.g., Twitter), social networks (e.g., Facebook), media sharing sites (e.g., You Tube), social bookmarking and voting sites (e.g., Digg and Reddit), review sites (e.g., Yelp), forums and virtual worlds (e.g., second life) (Zarrella, 2010).

Trottier and Fuchs (2015) differentiate SM relative to the type of social information these channels predominantly process. They distinguish three categories of SM: those which support cognition (e.g., web page), communication (e.g., e-mails) and cooperation (e.g., Facebook).

Numerous authors recognise the impact of SM on business, mostly highlighting their effect on marketing, management, governance, and strategic competitiveness (Kidd, 2011; Koushik et al., 2009; De Hertogh et al., 2011; Liu and Liu, 2009). Particular stress has been placed on the potential of SM to enable community building and stakeholder engagement. These potential benefits have been emphasised also with regard to cultural organisations. However early empirical researchers have devoted relatively less attention to museums, and only in recent years studies on SM and museums have begun to emerge (Kidd, 2011; Langa, 2014). The available research evidence on museums and SM suggests that museums strive to use SM as a means to promote community building and follower engagement.

This paper adds further evidence on this issue by empirically investigating whether museums are using the Facebook social environment to promote follower engagement. 
Our analysis is based on a sample of world's most visited museums observed over a period of six months (September 2018-February 2019).

The contribution of this study is multi-layered. Firstly, we provide quantitative data describing the Facebook posting activity of our sample museums. Secondly, we provide a qualitative representation of the posting activity by distinguishing museum-generated posts by their underlying structural and semantic features. Eventually we assess the impact of the overall museum posting activity and different content types on follower engagement measured by the cumulative number of follower reactions, these including like, share and comment reactions.

This remainder of this paper is organised as follows: Section 2 develops the conceptual framework for this study based on a review of the empirical literature on SM and museums; Section 3 explains the research methodology; Section 4 describes the research findings; the final Section 5 concludes the paper providing a discussion of the main results and outlining research limitations and future directions.

\section{Literature review}

The role of SM as innovative communication channels enabling cultural organisations to engage audiences in a targeted and interactive manner has increasingly been debated in the last few years. Kidd (2011) argues that the use of SM by museums can be a driving force to promote the image of the institution, the development of an online community that joins to the 'real' one and the participation to events and initiatives organised by museums.

Scholars (Minghetti et al., 2002) argue that museums can create economic and social value via SM since they break the traditional value chain (Camarero and Garrido, 2009; Camarero et al., 2012) potentially leading to improved dialogue with museums' visitors (Tasich and Villaespesa, 2013).

Although the potential benefits of SM for museums are widely agreed upon, empirical studies on museums and SM are relatively limited as compared to other private and publicly-run organisations (e.g., utilities). Moreover, the available empirical evidence suggests that the most common context of SM application by museums relates to promotional activities, focusing mainly on advertising upcoming exhibitions and events (Kotler et al., 2008).

Lopez et al. (2010) present cross-country findings on the presence of SM tools on museum websites indicating that two-way types of engagement were less frequent than individualised or passive visitation experiences. For the purposes of the present study, we refer to the term engagement as meaning a defined SM strategy used by museums that applies a bi-directional communication model on SM (Fletcher and Lee, 2012).

Schick and Damkjær (2010), in their analysis of Facebook profiles of Danish state-subsidised art museums, find that user engagement is generally limited and of poor quality, with most of the discussion rarely going beyond small talk and content shared lacking any apparent theoretical and cultural significance. They conclude that Danish museums were far away from a dialogic engagement, rather behaving as self-promoting 'friends'.

Based on a sample of 120 Spanish museums, Capriotti and Kuklinski (2012) seek to assess the level of dialogic communication developed by museums on the Internet by analysing the use of web platforms and social web applications with specific attention to 
content management and interaction management. They find that museums prioritise contents that provide general information about the institution and its products/services (collections, exhibitions and activities) over specific relevant information for each separate public of the institution. In their interaction management, museums basically use exhibitive resources for presenting information on their websites (fixed images and texts), make a very limited use of the Web 2.0 resources available (such as blogs, social networks, discussion forums and wikis) and mostly use passive information and feedback resources. The authors conclude that the museums studied are predominantly in a phase of 'monologic' communication and do not take full advantage of the interactive opportunities and resources of Internet and social web tools to create platforms that foster an open conversation and the establishment of 'dialogic' relations with their publics.

Similarly, a survey of American museums practitioners (Fletcher and Lee, 2012) indicates that SM are still underexploited as tools for dialogic engagement. Specifically, museum practitioners responded that they are using SM most often for event listings or posting reminder notices $(60 \%)$, to post online promotion or announcements $(45 \%)$ and to reach larger or new audiences (42\%). Only $11 \%$ of survey respondents indicated that they use SM for dialogic/conversational engagement, however, when asked about other uses of Twitter, museum practitioners indicated some two-way types of behaviour, including games or quizzes and engagement with other institutions.

Perhaps even more surprisingly, a study conducted on Catalonia Museums (Badell, 2015 ) finds that only $60 \%$ of Catalan museums present a SM profile of their own, and most of them are significantly lacking regarding feedback from their followers.

Lazzaretti et al. (2015) examine the case of the Museum of Natural History of Florence (MNHF), identifying potential advantages and challenges of using SM in a medium-sized cultural institution such as the MNHF. The case evidence indicates that different SM may perform specific roles in the communication strategy of museums, from the mere enhancement of visibility and geo-referentiation (Tripadvisor and Foursquare) to the collection of user-generated content (YouTube and Flickr) up to a broad variety of interactions (via Facebook and Twitter). However, in the case of MNHF, the organisational efforts to stimulate interactions with their followers via Facebook or Twitter were met by a relatively low level of follower engagement, suggesting that the choice to adopt SM and sustain the consequent organisational efforts (recruitment of dedicated staff) should be the result of a careful evaluation of the expected impacts and returns relative to alternative channels of communication. Furthermore, the authors stress the need to adopt a formal SM strategy to assign the museum presence on each SM specific objectives and targets consistent with the overall communication strategy.

Based on a sample of US museums, Langa (2014) explores the ways in which museums engage with followers through coding the content and frequency of their Twitter feeds. Through this analysis, the author seeks to understand whether follower engagement is driven by the type of 'dialogue' museums conduct with their online audience. He finds that the use of Twitter does not help US museums to increase the interaction with visitors, since museums use the platform mainly as a means to enhance their marketing practices, whereas engaging behaviours and opportunities for visitors to participate are much less frequent and underexploited.

Shaharir and Zanuddin (2018) analyse the case of the National Museum of Malaysia, focusing on the use of its Facebook page as a means to engage with followers. They find that this museum has a huge number of followers and though it achieves a poor level of 
follower engagement in terms of posts liked and shared. Accordingly, they suggest that the mere presence of SM per se does not yields engagement unless a true 'dialogue' is initiated by taking part to the existing conversations on SM page. On a similar note, based on the experience of Danish museums, Gronemann et al. (2015) argue that audience engagement and interaction is fuelled when the museum acknowledges its catalysing role as instigator and supporter of the communicative process.

Baker (2017) examines the use of Twitter on behalf of 27 science museums to determine what type of tweet yields more engagement with online audience as measured by the number of retweets and favourites. She finds that science museums use Twitter as a marketing tool for the majority of time, though marketing tweets generate a low number of follower reactions relative to tweets which are educational in content, suggesting that museums should enrich their promotional communication with educational-type content and also retweet visitors' museums experiences, create topics for discussion and share links to visitor-generated contents.

A research conducted by Contri et al. (2018) on Italian State museums indicates that although the use of SM is becoming more and more widespread, the approach towards SM continues to be almost exclusively communicational - that is, aimed to provide the public with information - since museums do not manage to involve and actively engage with followers. Similarly, Suzić et al. (2016) who examine SM engagement of museums from two European capitals - Berlin and Prague - document that museums of both groups predominantly post promotional content relating to announcements, events, ticket actions, exhibitions, special promotions and the like. However, they notice that a few museums take a more diversified approach to their online audience focusing additionally on posts containing educational and entertaining content and this approach seems to work in terms of stimulating fan reactions.

Overall there seems to be a need for further research on the use of SM on behalf of museums, particularly to shed light on what type of SM strategy can lead to follower engagement. In this regard, the related literature suggests that content is one major tool for developing a SM strategy that could effectively engage online visitors (Bernstein, 2008). Accordingly, the question arises as to what types of museum-generated content drive engagement and thereby the success of SM strategy.

Considering all the above, this study intends to contribute further empirical evidence on this research question based on an international sample of museums and focusing on the Facebook social environment through investigating the museums' degree of activity, the prevailing approach (content type) towards online audience and its effects in terms of follower reactions.

\section{Research methodology}

The purpose of this research is to analyse whether and to what extent the posting behaviour on SM promotes follower engagement using a sample of 16 museums ranking among the top-attended museums worldwide according to the Museum index released by the TEA/AECOM (2017). Top-attended museums are supposed to be a good indicator of the overall state of the industry and associated trends (TEA/AECOM, 2017). In other words, trends and activities at top-attended museums may signal what is currently occurring in the industry, particularly in such areas as investment, marketing, facility 
spending and technology adoption. Thus, we decided to focus on world's most 'popular' museums based on the assumption that they are at the forefront of efforts to engage with followers on SM platforms.

Facebook has been chosen as the reference online SM due to the following reasons. Based on the report of Statista (2019), Facebook has been identified as one of the most used SM by arts and culture organisations. Moreover, among the SM platforms Facebook is regarded as a highly valuable tool for fulfilling the strategic goals of both commercial and non-commercial organisations in that it supports three relevant social interactive features altogether, allowing users to create content, then to comment on generated content and finally to create new content based on the cooperation of many users. As such, Facebook social environment may enable museums to connect with their online audience at a suitable level to achieve community building and dialogic engagement, which represents an increasingly important aspect of their business development strategy.

The objectives of this study are manifold:

1 to quantitatively assess the presence of museums on Facebook (number of followers, posting frequency, follower reactions)

2 to analyse the posting behaviour of museums distinguishing posts by their semantic content and according to whether museums accompany posts with photo or video materials

3 to estimate the effects of posting activity on follower engagement, as measured by the cumulative number of likes, shares and comments per post.

These have been proposed in the literature as suitable metrics to evaluate follower engagement within the Facebook social environment (Bonsón and Ratkai, 2013; Bonsón et al. 2017; Haro-de-Rosario et al., 2018). Each of these metrics reflects different dimensions and levels of engagement: the number of likes measures the popularity of Facebook accounts, the number of comments measures the level of follower commitment and the number of shares measures the 'virality' of Facebook accounts (Bonsón and Ratkai, 2013). Following the afore-mentioned researchers, we summed up these metrics to obtain an aggregate index of engagement - the total number of follower reactions - which is deflated by the number of followers to adjust for differences in the size of audience.

In order to fulfil the research objectives, we used a quantitative methodology based on content analysis, a research technique based on the objective, systematic, and quantitative description of the manifest content of communication (Berelson, 1952). Content analysis is a flexible approach to the examination of various media, documents and texts, which seeks to quantify content in terms of predetermined categories and in a systematic and replicable manner (Bryman and Bell, 2015).

As a first step, we provide descriptive empirical evidence on the use of SM by sample museums, and then we perform a correlation analysis to evaluate the impact of content posted by museums on follower reactions. All statistical computations were performed using STATA 11.

Data were collected manually from the Facebook profile of each museum. The unit of data collection for the content analysis is each single post generated by sample museums on their official Facebook page. Specifically, we considered posts that were published between 1 September 2018 and 28 February 2019. 
Some tests were conducted to highlight ambiguous or unclear interpretation of the coding rules based on the content of the posts. The results were compared, and the difference of interpretation were discussed.

We have examined a total of 4,222 posts and, for each post, we have collected the number of likes, shares and comments.

\section{Findings}

This section first provides an overview of the data collected per museum and then describes the empirical analysis and its main results.

Table 1 shows the number of total followers, total posts and total reactions per museum as well as the number of likes, comments and shares as a percentage of total reactions.

Table 1 Overview of total followers, posts and reaction types per museum

\begin{tabular}{|c|c|c|c|c|c|c|}
\hline Museum & Followers & Posts & Reactions & Likes & Comments & Share \\
\hline National Palace Museum & 170,521 & 420 & 128,562 & $88 \%$ & $2 \%$ & $10 \%$ \\
\hline Tate Modern & $1,148,036$ & 360 & 298,774 & $76 \%$ & $5 \%$ & $19 \%$ \\
\hline National History Museum & 480,193 & 360 & 90,460 & $79 \%$ & $4 \%$ & $17 \%$ \\
\hline British Museum & $1,479,042$ & 99 & 280,095 & $75 \%$ & $3 \%$ & $22 \%$ \\
\hline Louvre Museum & $2,405,416$ & 134 & 166,794 & $84 \%$ & $3 \%$ & $13 \%$ \\
\hline Metropolitan Museum of Art & $1,891,955$ & 321 & 298,919 & $76 \%$ & $4 \%$ & $20 \%$ \\
\hline $\begin{array}{l}\text { American Museum of Natural } \\
\text { History }\end{array}$ & $1,172,877$ & 434 & 171,114 & $74 \%$ & $4 \%$ & $22 \%$ \\
\hline National Gallery & 932,652 & 372 & 339,894 & $81 \%$ & $2 \%$ & $17 \%$ \\
\hline $\begin{array}{l}\text { National Museum of American } \\
\text { History }\end{array}$ & 240,587 & 288 & 48,429 & $75 \%$ & $3 \%$ & $22 \%$ \\
\hline $\begin{array}{l}\text { National Air and Space } \\
\text { Museum }\end{array}$ & 321,139 & 188 & 47,583 & $81 \%$ & $4 \%$ & $15 \%$ \\
\hline National Gallery of Art & 844,426 & 104 & 69,229 & $79 \%$ & $2 \%$ & $19 \%$ \\
\hline Centre Pompidou & 685,693 & 337 & 78,864 & $78 \%$ & $3 \%$ & $19 \%$ \\
\hline Science Museum & 203,721 & 159 & 9,469 & $75 \%$ & $5 \%$ & $20 \%$ \\
\hline Musée d'Orsay & 808,944 & 207 & 184,662 & $82 \%$ & $3 \%$ & $15 \%$ \\
\hline Victoria and Albert Museum & 641,782 & 231 & 139,395 & $80 \%$ & $4 \%$ & $16 \%$ \\
\hline $\begin{array}{l}\text { Smithsonian's Museum of } \\
\text { Natural History }\end{array}$ & 253,264 & 208 & 39,780 & $78 \%$ & $3 \%$ & $19 \%$ \\
\hline MEAN & 855,015 & 264 & 149,501 & $79 \%$ & $3 \%$ & $18 \%$ \\
\hline
\end{tabular}

The museum with the highest number of followers is the Louvre $(2,405,416)$, while the museum with the highest number of posts (434) is the American Museum of Natural History. Instead, the museum with the lowest number of followers $(170,521)$ is the National Palace Museum. 
For each museum fans predominantly use the like function relative to the share and comment option. The prevalence of like reactions suggests that most museum-generated contents are not very engaging.

\subsection{Correlation between posting frequency and follower reactions}

The correlation between posting frequency and follower reactions is statistically significant (at $p<0.005)$ and fairly strong $(r=0.75)$ suggesting that on average follower reactions increase with an increasing number of posts. However, from Figure 1, we can observe two cluster of museums: the first one positioned above the regression line, indicating that some museums exhibit relatively low levels of posting frequency but achieve an above-average number of reactions; the second one positioned below the regression line, forming a group of museums with a lower number of reactions despite a higher posting frequency. This preliminary evidence suggests that follower reactions might be driven by the content type rather than the mere quantity of posts.

Figure 1 Fan reactions and Facebook posting activity (see online version for colours)

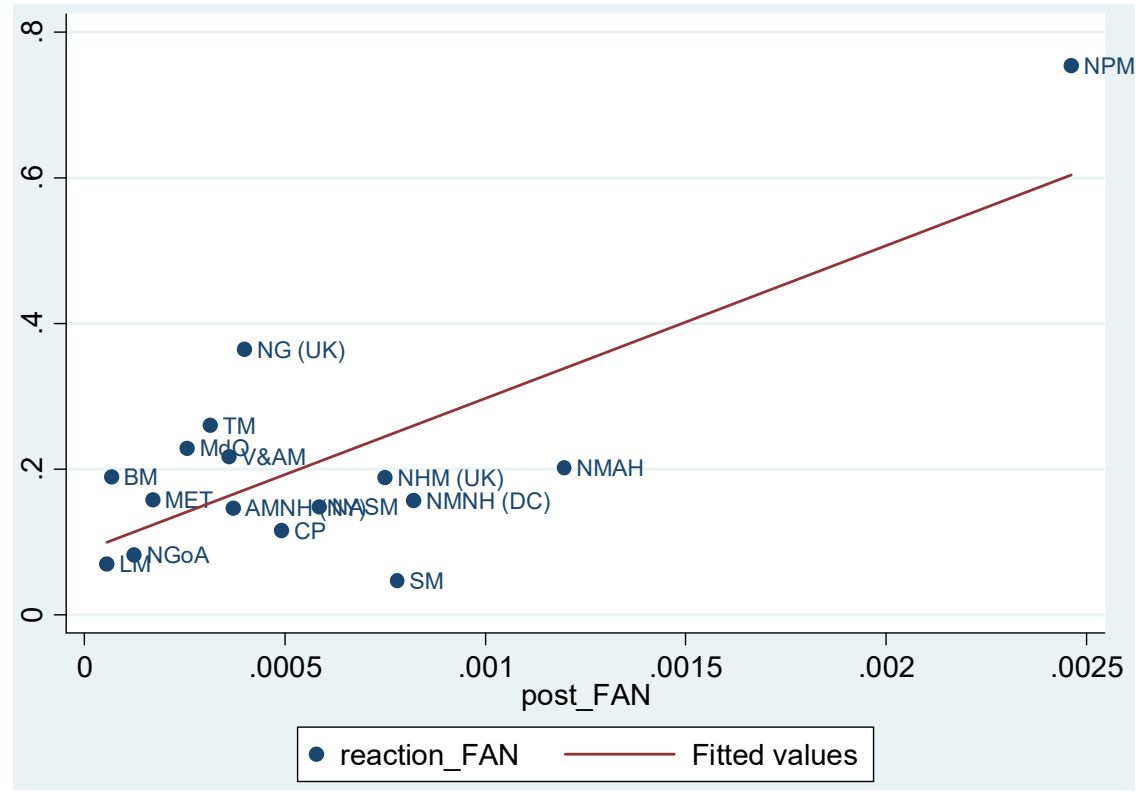

\subsection{Museum posting activity by visual media content}

In order to analyse whether museums enrich the content of their Facebook posts with visual media content, we have classified all published posts into three categories: posts which include photos (content D), posts which include videos (content E) and posts with no additional visual content (none).

Table 2 presents an overview of visual media contents used to enrich the content of Facebook posts. As shown, posts are often accompanied with an additional photo or video material. On average, posts with photos are more frequent than posts with videos. 
Table 2 Overview of posts with additional visual content

\begin{tabular}{lccc}
\hline Museum & Content D & Content E & None \\
\hline National Palace Museum & $45 \%$ & $1 \%$ & $44 \%$ \\
Tate Modern & $74 \%$ & $14 \%$ & $12 \%$ \\
National History Museum & $38 \%$ & $16 \%$ & $46 \%$ \\
British Museum & $85 \%$ & $15 \%$ & $0 \%$ \\
Louvre Museum & $62 \%$ & $22 \%$ & $16 \%$ \\
Metropolitan Museum of Art & $56 \%$ & $15 \%$ & $29 \%$ \\
American Museum of Natural History & $83 \%$ & $14 \%$ & $3 \%$ \\
National Gallery & $82 \%$ & $14 \%$ & $4 \%$ \\
National Museum of American History & $63 \%$ & $1 \%$ & $36 \%$ \\
National Air and Space Museum & $54 \%$ & $26 \%$ & $20 \%$ \\
National Gallery of Art & $100 \%$ & $0 \%$ & $0 \%$ \\
Centre Pompidou & $71 \%$ & $26 \%$ & $3 \%$ \\
Science Museum & $83 \%$ & $16 \%$ & $1 \%$ \\
Musée d'Orsay & $80 \%$ & $20 \%$ & $0 \%$ \\
Victoria and Albert Museum & $84 \%$ & $15 \%$ & $1 \%$ \\
Smithsonian's National Museum of Natural History & $73 \%$ & $1 \%$ & $26 \%$ \\
MEAN & $71 \%$ & $14 \%$ & $15 \%$ \\
\hline
\end{tabular}

Figure 2 Correlation of follower reactions and posts with photos (see online version for colours)

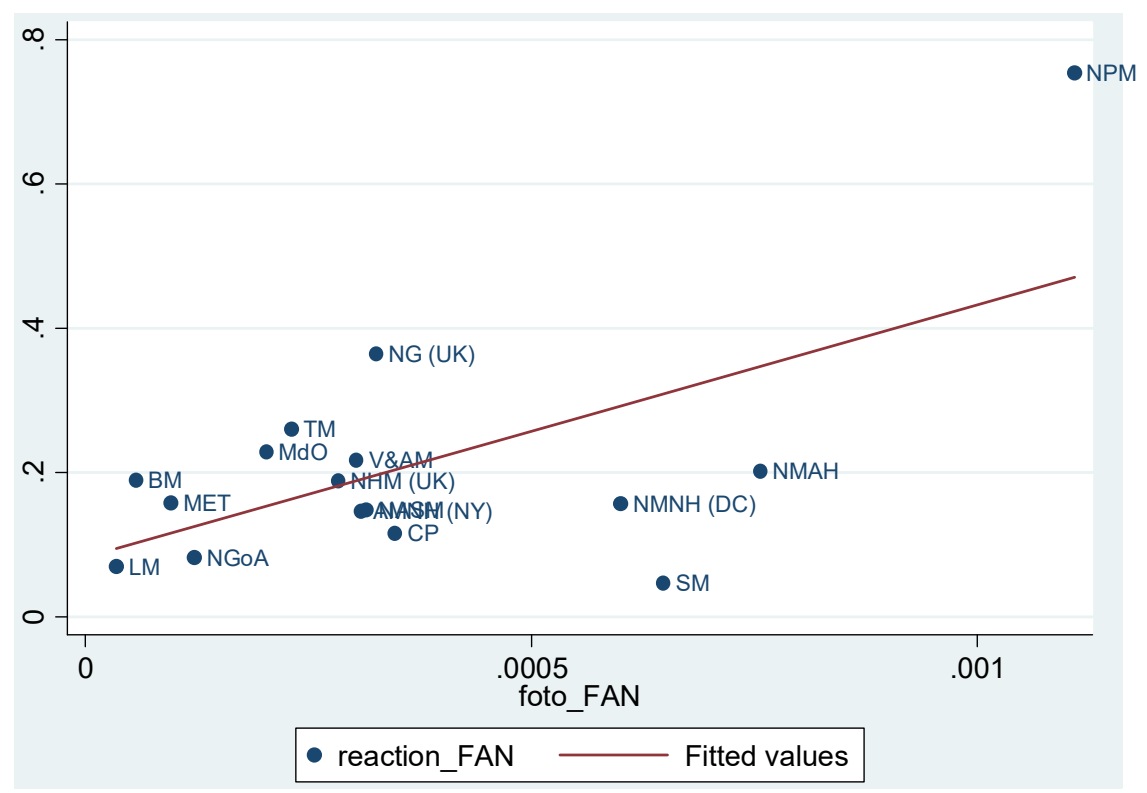




\subsection{Reaction of followers to visual media content}

The analysis of correlation between follower reactions and posts with visual content provides mixed results. Specifically, we found a positive and statistically significant correlation (untabulated) between follower reactions and posts with photos $(r=0.60908$ with $p<0.05$ ), whereas the correlation between follower reactions and the number of posts with videos is virtually null $(r=-0.0154)$. These findings are presented in Figures 2 and 3 .

Figure 3 Correlation of follower reactions and posts with videos (see online version for colours)

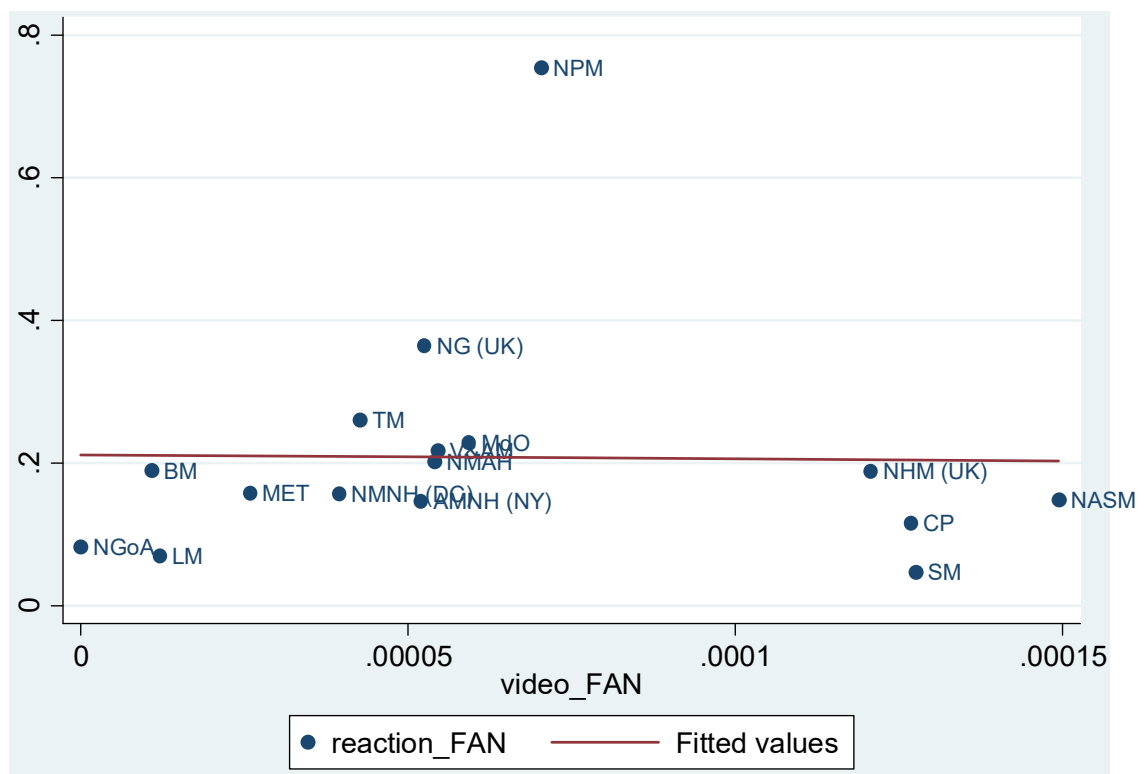

\subsection{Semantic structure of posts}

Following Suzić et al. (2016), we also classify museum posts by their semantic structure into three further categories.

Each category highlights a particular effect of Facebook posts - promotional, educational and entertaining - which is intended to stimulate follower engagement to different degrees. These categories are labelled as follows:

1 Category A (promotional) posts: They mainly provide information on upcoming events or exhibitions.

2 Category B (educational) posts: They cover insights into the general field of museums' activity, without direct promotional acts meant to inform the public on upcoming events or exhibitions.

3 Category $\mathrm{C}$ (entertaining) posts: They provide entertainment content without promotional or educational intent with the main purpose to provide fun for audiences, thus amplifying museum communication on an informal level. 
An overview of the content categories of museum posts is provided in Table 3. It emerges that sample museums predominantly post contents related to category B. The least used semantic category relates to posts belonging to category $\mathrm{C}$.

Table 3 Overview of content categories of posts per museum

\begin{tabular}{lccc}
\hline Museum & Content A & Content B & Content C \\
\hline National Palace Museum & $49 \%$ & $42 \%$ & $9 \%$ \\
Tate Modern & $24 \%$ & $63 \%$ & $13 \%$ \\
National History Museum & $37 \%$ & $47 \%$ & $16 \%$ \\
British Museum & $46 \%$ & $43 \%$ & $11 \%$ \\
Louvre Museum & $54 \%$ & $18 \%$ & $28 \%$ \\
Metropolitan Museum of Art & $42 \%$ & $50 \%$ & $8 \%$ \\
American Museum of Natural History & $10 \%$ & $85 \%$ & $5 \%$ \\
National Gallery & $55 \%$ & $45 \%$ & $1 \%$ \\
National Museum of American History & $32 \%$ & $67 \%$ & $1 \%$ \\
National Air and Space Museum & $37 \%$ & $40 \%$ & $23 \%$ \\
National Gallery of Art & $23 \%$ & $76 \%$ & $1 \%$ \\
Centre Pompidou & $61 \%$ & $38 \%$ & $1 \%$ \\
Science Museum & $37 \%$ & $60 \%$ & $3 \%$ \\
Musée d'Orsay & $88 \%$ & $12 \%$ & $0 \%$ \\
Victoria and Albert Museum & $55 \%$ & $44 \%$ & $1 \%$ \\
Smithsonian's National Museum of Natural History & $35 \%$ & $59 \%$ & $6 \%$ \\
MEAN & $41 \%$ & $47 \%$ & $7 \%$ \\
\hline
\end{tabular}

\subsection{Reactions induced by specific semantic categories}

Table 4 provides an overview of the correlation between the above content categories and the total number of follower reactions (likes, shares and comments).

The Pearson's correlation analysis provides mixed results. In fact, the correlation coefficient between follower reactions and A category posts (promotional content) is positive $(r=0.6844)$ and statistically significant (at $p \leq 0.01)$ while the coefficients relating to $\mathrm{B}$ (educational) and $\mathrm{C}$ (entertaining) category posts is not statistically significant.

Table 4 Correlation analysis of content categories and follower reactions

\begin{tabular}{lccc}
\hline & Content $A$ & Content B & Content C \\
\hline Reactions & $0.6844^{* * *}$ & 0.3285 & -0.1970 \\
\hline
\end{tabular}

Notes: $* * * * *, *$ indicate statistical significant at $p \leq 0.001,0.01$ and 0.05 , respectively.

Again, the graphical representation could provide more insights into these relationships. This is provided in Figures 4 to 6.

In Figure 4, we can observe that museums positioned above the regression line achieve a higher number of follower reactions to their promotional (A) posts relative to 
the museums positioned below the regression line, which suggests that some museums are more effective than others at promoting their products and events.

Figure 4 Correlation of follower reactions and promotional (A) posts (see online version for colours)

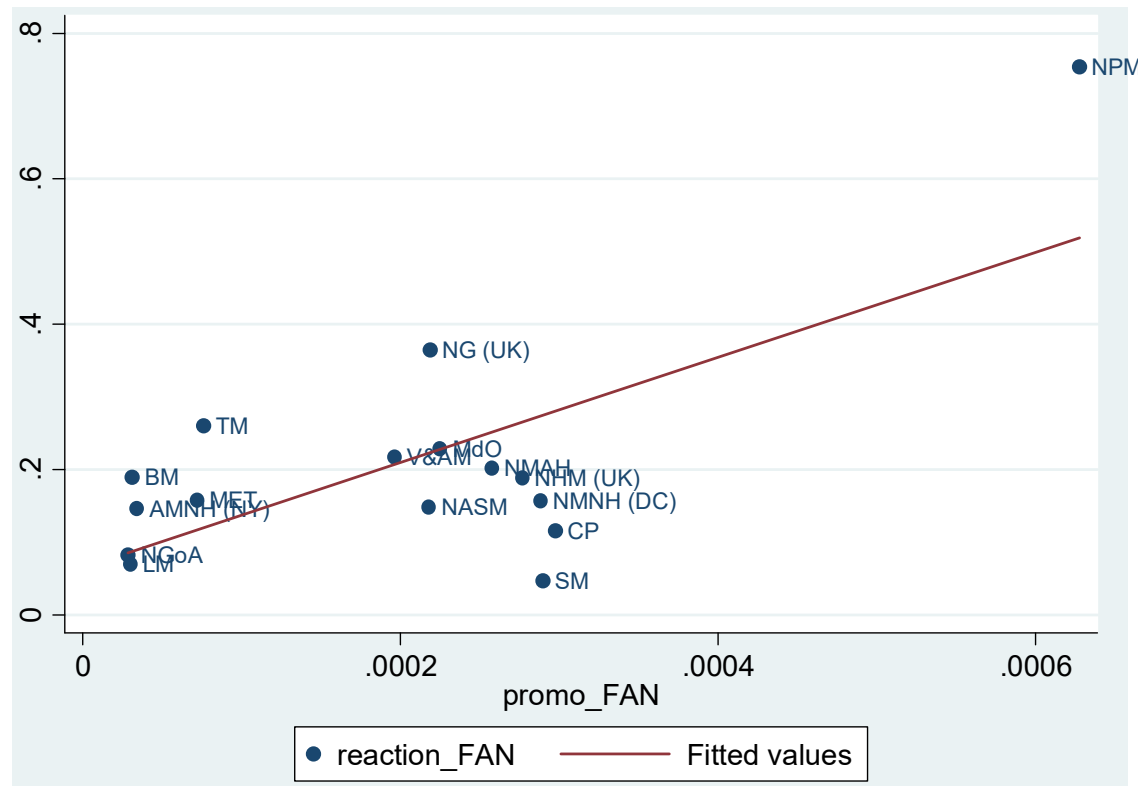

Figure 5 Correlation of follower reactions and educational (B) posts (see online version for colours)

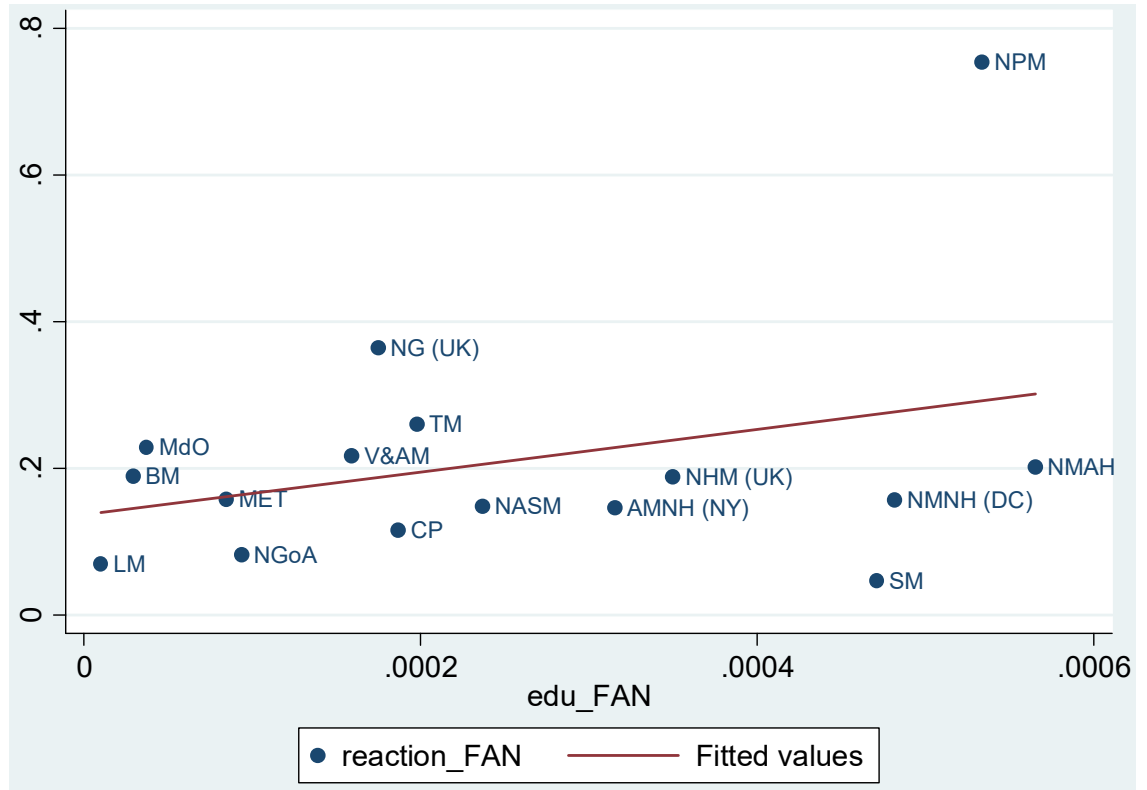


Instead, regarding the impact of educational (B) posts, we can observe (Figure 5) that data points tend to lie near the $\mathrm{X}$ axis indicating that follower reactions in most cases are weakly correlated with the number of educational posts, even though there are some significant outliers positioned above the regression line (namely, the National Gallery and the National Palace Museum).

Regarding entertainment $(\mathrm{C})$ posts, we can observe (Figure 6) that the majority of data points lie near the $\mathrm{Y}$ axis indicating that follower reactions are virtually independent from the number of $\mathrm{C}$ posts generated by museums.

Figure 6 Correlation of follower reactions and entertaining (C) posts (see online version for colours)

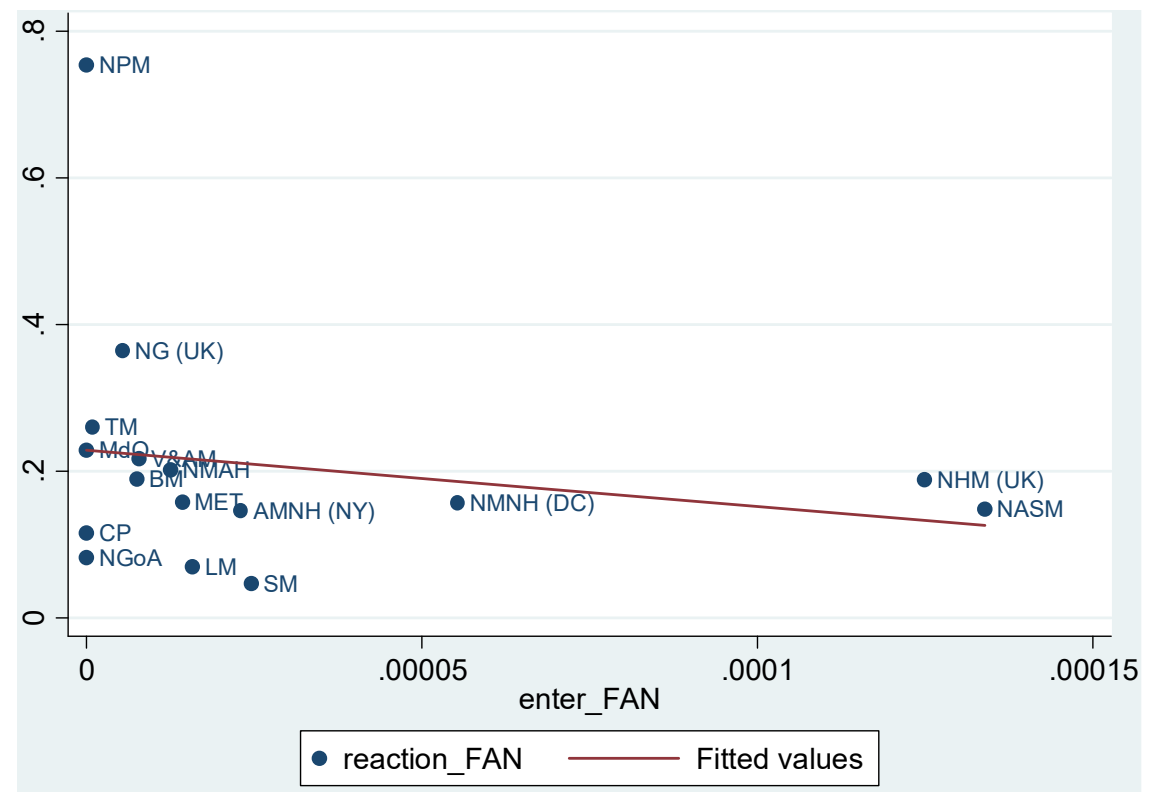

\section{Conclusions and future research directions}

This study adds to the recently growing literature analysing the actual use of SM by museums and its impact in terms of follower engagement. As such, this study has first assessed quantitatively the presence, the frequency and the content features of SM activity of an international sample of museums via a content analysis of their posting activity observed over a six-month period. The research setting was Facebook - one of the SM platforms predominantly used by profit and non-profit oriented organisations. We have then analysed whether content type had a differentiated impact in terms of follower engagement as measured by the usage of Facebook interactive features on behalf of museums' followers.

Consistent with previous research in the field, our analysis revealed that SM utilisation by sample museums is mainly geared towards promotional activities which are not conducive to a true dialogic engagement between museums and their online audiences, as suggested by the finding that the most dominant type of follower reaction in 
average terms is the 'like' reaction. It implies that museums should develop strategies based on content types that generate follower involvement in a more diversified and engaging manner. Practically, the focus should be shifted from currently dominant like reactions to other features of Facebook social environment, which include sharing and commenting facilities. The finding that the comment function - which allows for bidirectional communication and enables user engagement - is used to the lowest extent in our sample provides an indication of the scant effectiveness of the SM strategy employed by sample museums. It suggests they are not fully exploiting the potential of the Facebook platform, leading a 'dialogue' that is promoting only a suboptimal engagement of online audiences. Following prior researchers (Tasich and Villaespesa, 2013), we suggest that museums should take into account the mission and goal of their particular institution and structure their SM strategy accordingly.

Our analysis has also revealed that follower reactions significantly correlate with posts accompanied by photo material, which corroborates the claim that users show positive attitudes towards photo media content (Spiliopoulou et al., 2014). Additionally, when analysing our dataset at individual level, we found that some museums post more diversified and engaging content than simple promotional posts and they represent significant outliers in term of follower reactions. This suggest that the success of museums in engaging followers might be driven up if the semantic structure of the posts incorporates educational and entertainment tools in addition to the usual promotional messages.

Admittedly, this study suffers from several limitations, mainly due to the limited number of variables used to proxy follower engagement and the relative small sample size. Thus, our research could be extended by including institutions from entire national regions to account for the impact of political, economic and cultural factors on museums' SM strategies, and/or by investigating homogenous groups of museums clustered by their specific activities (e.g., natural history, science). Even more significantly, future studies should include the analysis of the effectiveness of SM strategy from the standpoint of museum visitors. A recent research of this kind has been carried out by Waller and Waller (2018) who analyse the negative comments posted on the Facebook review sites of the major US and Australian art museums.

Eventually, considering the presence of significant outliers in our analysis, we do advise future researchers to use more fine-gained metrics of follower engagement in order to provide a more detailed mapping and understanding of the key factors driving the success of SM strategies of culture organisations.

\section{References}

Badell, J-I. (2015) 'Museums and social media: Catalonia as a case study', Museum Management and Curatorship, Vol. 30, No. 3, pp.246-263.

Baker, S. (2017) 'Identifying behaviors that generate positive interactions between science museums and people on Twitter', Museum Management and Curatorship, Vol. 32, No. 2, pp.144-159.

Berelson, B. (1952) Content Analysis in Communication Research, Free Press, New York.

Bernstein, S. (2008) 'Where do we go from here? Continuing with Web 2.0 at the Brooklyn Museum', in Trant, J. and Bearman, D. (Eds.): Museums and the Web 2008: Proceedings, Toronto Archives \& Museum Informatics, Toronto, Canada, pp.37-47. 
Bonsón, E. and Ratkai (2013) 'A set of metrics to assess stakeholder engagement and social legitimacy on a corporate Facebook page', Online Information Review, Vol. 37, No. 5, pp.787-803.

Bonsón, E., Royo, S. and Raktai, M. (2017) 'Facebook practices in Western European municipalities: an empirical analysis of activity and citizen engagement?', Administration and Society, Vol. 49, No. 3, pp.320-347.

Bryman, A. and Bell, E. (2015) Business Research Methods, Oxford University Press, Oxford.

Camarero, C. and Garrido, M-J. (2009) 'Improving museums' performance through custodial, sales, and customer orientations', Nonprofit and Voluntary Sector Quarterly, Vol. 38, No. 5, pp.846-868.

Camarero, C., Garrido-Samaniego, M.J. and Vicente, E. (2012) 'Determinants of brand equity in cultural organizations: the case of an art exhibition', The Service Industries Journal, Vol. 32, No. 9, pp.1527-1549.

Capriotti, P. and Kuklinski, H.P. (2012) 'Assessing dialogic communication through the internet in Spanish museums', Public Relations Review, Vol. 38, No. 4, pp.619-626.

Contri, M., Fissi, S., Gori, E. and Romolini, A. (2018) 'Musei statali e social media: chi e cosa 'piace'?', VII Workshop della Rivista Management Control, 'Controlli interni e di gestione: generazione di valore e tutela dei diversi portatori di interesse'.

De Hertogh, S., Viaene, S. and Dedene, G. (2011) 'Governing Web 2.0', Communication of the $A C M$, Vol. 54, No. 3, pp.124-130.

Fletcher, A. and Lee, M.J. (2012) 'Current social media uses and evaluations in American museums', Museum Management and Curatorship, Vol. 27, No. 5, pp.505-521.

Gronemann, S.T., Kristiansen, E. and Drotner, K. (2015) 'Mediated co-construction of museums and audiences on Facebook', Museum Management and Curatorship, Vol. 30, No. 3, pp.174-190.

Haro-de-Rosario, A., Sáez-Martin, A. and del Carmen Caba-Pérez, M. (2018) 'Using social media to enhance citizen engagement with local government: Twitter or Facebook?', New Media \& Society, Vol. 20, No. 1, pp.29-49.

Kaplan, A.M. and Haenlein, M. (2010) 'Users of the world, unite! The challenges and opportunities of social media', Business Horizons, Vol. 53, No. 1, pp.59-68.

Kidd, J. (2011) 'Enacting engagement online: framing social media use for the museum', Information Technology \& People, Vol. 24, No. 1, pp.64-77.

Kotler, N.G., Kotler, P. and Kotler, W.I. (2008) Museum Marketing and Strategy: Designing Missions, Building Audiences, Generating Revenue and Resources, 2nd ed., Jossey-Bass, San Francisco, CA.

Koushik, S., Birkinshaw, J. and Crainer, S. (2009) 'Using Web 2.0 to create management 2.0', Business Strategy Review, Vol. 20, No. 2, pp.20-23.

Langa, A.L. (2014) 'Does Twitter help museum engage with visitors?', in iConference 2014 Proceedings, pp.484-495.

Lazzaretti, L., Sartori, A. and Innocenti, N. (2015) 'Museums and social media: the case of the Museum of Natural History of Florence', International Review on Public and Nonprofit Marketing, Vol. 12, No. 3, pp.267-283.

Liu, C-H. and Liu, H-S. (2009) 'Increasing competitiveness of a firm and supply chain with Web 2.0 initiatives', International Journal of Electronic Business Management, Vol. 7, No. 4, pp.248-255.

Lopez, X., Margapoti, I., Maragliano, R. and Bove, G. (2010) 'The presence of Web 2.0 tools on museum websites: a comparative study between England, France, Spain, Italy, and the USA', Museum Management and Curatorship, Vol. 25, No. 2, pp.235-249.

Minghetti, V., Moretti, A. and Micelli, S. (2002) 'Reengineering the museum's role in the tourism value chain: towards an IT business model', Information Technology \& Tourism, Vol. 4, No. 2, pp.131-143. 
Schick, L. and Damkjær, K. (2010) 'Can you be friends with an art museum? Rethinking the art museum through Facebook', in Aljas, A. (Ed.): Transforming Culture in the Digital Age, Proceedings of the International Conference in Tartu, University of Tartu, Tartu, pp.34-42.

Shaharir, S.A. and Zanuddin, H. (2018) 'Museum institutions in the digital age: the insights of Malaysian museums' use of Facebook', The Journal of Social Sciences Research, pp.357-366.

Spiliopoulou, A-Y., Mahony, S., Routsis, V. and Kamposiori, C. (2014) 'Cultural institutions in the digital age: British Museum's use of Facebook Insights', Participations: Journal of Audience \& Reception Studies, Vol. 11, No. 1, pp.286-303.

Statista (2019) [online] https://www.statista.com/statistics/264810/number-of-monthly-activefacebook-users-worldwide/ (accessed 26 March 2019).

Suzić, B., Karlíček M. and Stř́teský, V. (2016) 'Social media engagement of Berlin and Prague museums', The Journal of Arts Management, Law, and Society, Vol. 46, No. 2, pp.73-87.

Tasich, T. and Villaespesa, E. (2013) 'Meeting the real user: evaluating the usability of Tate's Website', in Proctor, N. and Cherry, R. (Eds.): Museums and the Web 2013, Silver Spring, Museums and the Web, MD [online] https://mw2013.museumsandtheweb.com/paper/meetingthe-real-user-evaluating-the-usability-of-tates-website/ (accessed 26 March 2019).

Themed Entertainment Association and AECOM (TEA/AECOM) (2017) Theme Index and Museum Index: The Global Attractions Attendance Report, Themed Entertainment Association (TEA) [online] http://www.teaconnect.org/images/files/ TEA_268_653730_180517.pdf (accessed 12 March 2019).

Trottier, D. and Fuchs, C. (2015) Social Media, Politics and the State. Protests, Revolutions, Riots, Crime and Policing in the Age of Facebook, Twitter and YouTube, 1st ed., Routledge, New York.

Waller, D.S. and Waller, H.J. (2018) 'An analysis of negative reviews in top art museums' Facebook sites', Museum Management and Curatorship [online] https://www.tandfonline.com/doi/abs/10.1080/09647775.2018.1550622?casa_token=cOUggGFF9gAAAAA:beB3JNTgg31ci8QJFC5rOSvkhIjtsAw3FqEklHZk5udGxUüUxQvsf3qMyBf xPgELna16_K2uVI4 (accessed 30 March 2019).

Zarrella, D. (2010) The Social Media Marketing Book, 1st ed., O’Reilly, Sebastopol, Canada. 